\title{
Erratum to: A Nonlinear Generalization of Singular Value Decomposition and Its Applications to Mathematical Modeling and Chaotic Cryptanalysis
}

\author{
Prabhakar G. Vaidya • Sajini Anand P. S • \\ Nithin Nagaraj
}

Published online: 6 February 2010

(C) Springer Science+Business Media B.V. 2010

\section{Erratum to: Acta Appl Math \\ DOI 10.1007/s10440-010-9560-z}

Unfortunately a few errors were left uncorrected during the proof process of this paper. They are listed here:

1. Section 8: in the second last paragraph, in line number 3: "Figures 4(i) and (ii)" should read "Figures 5(i) and (ii)".

2. Section 8: in the second to last paragraph, in line number 4: "Figures 4(iii) and (iv)" should read "Figures 5(iii) and (iv)".

3. Section 9: in the figure caption for Fig. 6, in line 1: "generated by Team A" should read "generated from Van der Pol equation".

4. Section 9: in the figure caption for Fig. 6, in line 2: "was sent to Team B" should read "was used for modeling".

5. We apologize for the presence of the uncited references $12,13,33,34$, and 35 in the Reference section.

The online version of the original article can be found under doi:10.1007/s10440-010-9560-z.

P.G. Vaidya $\cdot$ S. Anand P. S (凶)

National Institute of Advanced Studies, Indian Institute of Science Campus, Bangalore 560 012, India

e-mail: sachoo@gmail.com

P.G. Vaidya

e-mail:pgvaidya@yahoo.com 